\title{
Sob comando deles: as barreiras para mulheres técnicas nas equipes olímpicas brasileiras
}

Under their Command: Barriers for Women Coaches in Brazilian Olympic Teams

William Douglas de Almeida jornalismo_william@yahoo.com.br Doutor em Ciências pela Escola de Educação Física e Esporte da Universidade de São Paulo/Brasil e membro do Grupo de Estudos Olímpicos da Universidade de São Paulo, Brasil

Rovilson de Freitas rovilson.freitas@usp.br

Mestrando em em Banco de Dados e Recuperação da Informação, no Instituto de Ciências Matemáticas e de Computação da Universidade de São Paulo em São Carlos/Brasil e membro do Grupo de Estudos Olímpicos da Universidade de São Paulo, Brasil (iD) https://orcid.org/0000-0002-2646-2241

Recepção: 23 Julho 2020 Aprovação: 06 Setembro 2020 Publicação: 09 Outubro 2020

Cita sugerida: Almeida, W. D. de y Freitas, R. de (2020). Sob comando deles: as barreiras para mulheres técnicas nas equipes olímpicas brasileiras. Educación Física y Ciencia, 22(4), e156. https://doi.org/10.24215/23142561e156
Resumo: Este artigo tem como objetivo discutir os obstáculos impostos a mulheres brasileiras para assumir cargos como treinadoras em seleções nacionais. Como método, é feita uma revisão bibliográfica sobre a temática e trabalha-se com a narrativa biográfica da única mulher a comandar uma seleção brasileira de uma modalidade coletiva em Jogos Olímpicos, Maria Helena Cardoso, técnica do time de basquete em Barcelona-1992. Como resultados e conclusões, constata-se que ainda há um machismo no esporte brasileiro, que impede às mulheres ascender a cargos de comando em equipes nacionais.

Palavras-chave: Basquete feminino, Jogos Olímpicos, Treinadoras, Discriminação, Machismo.

Abstract: This article aims at discussing the obstacles imposed on Brazilian women to assume positions as coaches in national teams. As a method, a bibliographic review on the theme was performed as well as a biographical narrative of the only woman to lead a Brazilian team in a collective modality in the Olympic Games, Maria Helena Cardoso, a basketball team coach in Barcelona-1992. As a result, and conclusion, it appears that there is still sexism in the Brazilian sport, mainly for women to ascend to positions of command in national teams.

Keywords: Women's basketball, Olympic Games, Coaches, Discrimination, Sexism.

\section{Introdução}

Participar de uma edição olímpica é um sonho para a maioria dos personagens envolvidos com o esporte. Durante muitos anos, porém, este sonho foi sonegado a diversas mulheres que optaram pela prática de modalidades coletivas. São várias as modalidades que comprovam o quanto o sexismo marcou o movimento olímpico ao longo do século passado. A primeira modalidade coletiva a permitir a participação de mulheres foi o vôlei, juntamente com os homens, em sua estreia olímpica 
em 1964. Também iniciaram juntos, homens e mulheres, o rugby sevens, em 2016. O basquete feminino, apenas em 1976, sendo que os homens estavam no programa desde 1936. O hóquei na grama permitiu a participação feminina em 1980, enquanto os homens iniciaram sua caminhada nos Jogos em 1908. No handebol, a diferença foi mais curta: 1972 para os homens, 1976 para as mulheres. No futebol, as mulheres só participaram de sua primeira edição olímpica em 1996, 96 anos depois dos homens. Tempo menor apenas às das mulheres do polo aquático: 100 anos (elas em 2000, eles em 1900).

Se a barreira para as atletas demorou tanto tempo a cair, para aquelas que se aventuraram no cargo de treinadoras o caminho foi ainda mais longo. Ferreira (2012) lista uma série de obstáculos enfrentados pelas mulheres que tentam a carreira de treinadoras esportivas, dentre eles "o preconceito, questionamentos de competência e capacidade de liderança feminina, conflito da vida profissional e pessoal, baixos salários e estereótipos" (p.23). De acordo com a autora, isso ocorre porque há uma associação entre treinamento esportivo e masculinidade, o que acaba dificultando o acesso das mulheres a este trabalho. A situação, todavia, não é exclusiva das brasileiras. Acosta e Carpenter (2014) mantém um estudo longitudinal sobre o número de mulheres atuando como técnica nos Estados Unidos, e apontam para a discrepância existente entre o número de homens e mulheres atuando como técnicos nas ligas universitárias. De acordo com as autoras, em 2014, apenas quatro em cada dez técnicas de equipes femininas eram mulheres, sendo que este número está em crescimento. No caso das equipes masculinas, $97 \%$ eram comandadas por homens. Ao analisar o futebol, Fastin e Pfister (2000) comprovaram que mesmo os técnicos homens eram a maioria em países europeus como a Alemanha, Suécia e Noruega. Reade, Rodgers e Norman, (2009) abordam a mesma problemática no Canadá.

Ao analisar a função dos treinadores esportivos, Fetter e Silva (2011) apontam que o técnico carrega uma aura especial, tendo em vista que seus conhecimentos vão além da parte prática do jogo: são acumulados os papeis de estrategista, líder, chefe, tornando-se em muitos casos uma figura próxima a do professor, alcunha com a qual muitos acabam sendo chamados pelos atletas. Com tantas responsabilidades envolvidas no cargo, o que se espera de alguém para assumir tal função é o domínio da modalidade, mas também a capacidade de gerenciar pessoas, assumir responsabilidades e comandar um conjunto de pessoas que possam extrair o melhor dos atletas dentro dos campos ou quadras.

De acordo com Goellner (2006) a entrada das mulheres no cenário esportivo brasileiro não ocorreu por conta de políticas públicas, ou de programas que promovessem a equidade de gênero, mas sim de esforços individuais e de enfrentamentos que foram realizados pelas pioneiras. Reade et al. (2009) detectam que em algumas competições individuais as mulheres conseguem ocupar o cargo de técnicas e funções diretivas, com uma representatividade um pouco mais significativa. No caso do Brasil, Amato (2018) aponta como pioneira no atletismo Benedicta de Oliveira. 
Após ter participado da edição dos Jogos Olímpicos de Londres-1948, Benedicta Oliveira se formou em educação física e se tornou a primeira mulher técnica do atletismo brasileiro, também tendo que enfrentar muitas barreiras para conseguir iniciar seus trabalhos. No início atuou como técnica das equipes femininas do Clube Espéria e, em 1965 foi convidada para comandar a seleção brasileira de atletismo no Campeonato Sul-Americano. Também atuou como supervisora das equipes femininas de atletismo nas edições dos Jogos Pan-Americanos de 1971, 1975 e 1983, e também nos Jogos Olímpicos de Montreal 1976. (p. 107)

A história de luta das mulheres para terem acesso à prática esportiva faz com que a presença feminina nos diferentes papeis do esporte ganhe um status de empoderamento, segundo Adelman (2004). A autora, porém, pondera que é necessário ficar atento às condições ofertadas para que isso ocorra e para o contexto em que a participação feminina ocorre sendo que a valorização social da mulher na prática desportiva pode variar segundo este contexto.

Balbino (2005) rotula o técnico como o agente da pedagogia do treinamento. Segundo o autor, esta é uma função que exige uma série de conhecimentos em áreas bastante diversificadas, sendo que o número de exigências para desempenhar tal função é grande. Não basta o conhecimento prático sobre a modalidade, o conhecimento técnico deve ser aliado a diversos outros domínios, como a capacidade de comunicação com o grupo, o domínio de questões biológicas para saber dosar as cargas de treinamento, a capacidade de planejamento para condução e organização de treinos, extraindo assim o máximo da equipe, o raciocínio lógico apurado e rápido, para tomar decisões rápidas durante a realização das partidas, dentre outras.

Não por acaso, parte dos treinadores esportivos alcança este cargo após anos de preparo acadêmico ou trabalhando como professores de modalidades esportivas de crianças e jovens. Todavia, em entrevistas com atletas de ligas inglesas, Shaw e Hoeber (2003) constatam que no discurso de vários atletas uma visão sexista com relação a estes profissionais

Os papéis desempenhados por técnicos e professores estavam repletos de discursos conflitantes entre masculinidade e feminilidade. Dentro das três organizações de estudo de caso, o ensino estava claramente associado a discursos de feminilidades e às qualidades de carinho e carinho incorporadas a elas. [...] As professoras foram percebidas, por muitos entrevistados, como pessoas que trabalham com jovens atletas até o trabalho 'real' de treinadores começar. Por outro lado, o papel do treinador estava associado a discursos duros, competitivos e masculinos, pois eram responsáveis por garantir que os atletas ganhassem medalhas e trouxessem glória. (p. 168-369, tradução dos autores)

Assim, não basta às mulheres a qualificação técnica e prática, e o domínio de todas as habilidades exigidas dos demais treinadores. É preciso provar a todo momento que elas não são simplesmente "professoras", mas sim profissionais que podem trabalhar com o alto rendimento.

Não por acaso, é mais comum que se encontre treinadoras mulheres em modalidades exclusivamente femininas, como a ginástica rítmica, onde a presença feminina costuma extrapolar os limites dos tablados. Em quatro edições olímpicas o Brasil enviou equipes para a disputa de conjuntos e, em todas elas, as técnicas foram mulheres. Bárbara Laffranchi esteve à 
frente em 2000 e 2004; Monika Queiroz, em 2008, e Camila Ferezin foi a técnica brasileira nos Jogos Olímpicos do Rio de Janeiro, em 2016. Em outra modalidade até então exclusivamente feminina, o nado artístico, o Brasil estreou na prova de conjuntos em 2016 sob o comando da treinadora Maura Xavier. Em um estudo realizado no Canadá, Reade et al. (2009) constatam um fenômeno semelhante, com as mulheres prioritariamente trabalhando nestas modalidades

Os resultados atuais sustentam a hipótese de uma hegemonia masculina no esporte que precisa ser mantida (por exemplo, a predominância de homens em posições de poder na maioria dos esportes) limitando as mulheres aos esportes 'tradicionalmente femininos', como a patinação artística e o nado artístico, e a níveis mais baixos de treinamento. Os dados atuais indicam que limitar o trabalho de mulheres técnicas a ao comando de equipes femininas em esportes coletivos também pode estar funcionando como um método de marginalização (p.518, tradução dos autores)

Theberge (1993) corrobora tal visão, acrescentando que a presença de treinadoras mulheres em modalidades exclusivamente femininas acaba criando uma falsa sensação de equilíbrio de gênero, tendo em vista que este espaço é ocupado pelas mulheres.

Ao observar as modalidades coletivas que são disputadas nos Jogos Olímpicos por atletas de ambos os sexos, foram 30 participações de equipes brasileiras (dez no vôlei, sete no basquete, seis no futebol, cinco no handebol e uma no rúgbi e no polo aquático). Dentro de todo este universo, apenas um time teve uma mulher no comando: o basquete em 1992. Ou, talvez seja melhor chamar de "o time de Maria Helena", tal o grau de identificação entre a treinadora e aquela seleção. Das equipes femininas brasileiras classificadas para a próxima edição olímpica, em Tóquio, há apenas uma comandada por uma mulher: o futebol, que terá a sueca Pia Sundhage, contratada em 2019.

Inédita até este momento, a participação de Maria Helena poderia não ter ocorrido. Ao chegar à Vila Olímpica, em Barcelona, a treinadora redigiu uma carta de demissão, na qual explicava os motivos que a faziam desistir de realizar o sonho de participar de uma edição olímpica. A ideia, porém, foi abandonada após ouvir algumas pessoas de sua comissão técnica, em especial a assistente Heleninha, escudeira durante toda a carreira. Aliás, quando questionada sobre a razão de ter suportado tantas pressões e ter conseguido ser a técnica da seleção, ela não refuta "Só aguentamos porque éramos duas" (Maria Helena, comunicação pessoal, 20 de maio de 2018). Uma trajetória que começou muitos anos antes, dentro de quadra.

\section{Metodologia: A escolha pela escuta}

A presença de uma única mulher no cargo de técnica de uma equipe nacional brasileira faz com que Maria Helena torne-se um exemplo de exceção que confirma a regra: no Brasil, os cargos de comando do esporte ainda concentram-se nas mãos de homens. A busca pela compreensão das razões deste fenômeno nos levou até a única treinadora que conseguiu 
furar este bloqueio. Apesar de estar afastada das quadras há quase duas décadas, procuramos Maria Helena para que ela falasse sobre sua trajetória.

Optamos então pela metodologia da narrativa biográfica, assim, não adotamos nenhum questionário ou buscamos a comprovação de teorias ou a confirmação de dados na entrevista que realizamos. Dentre as vantagens de se trabalhar desta maneira, Rubio (2014) aponta que a realização de uma entrevista mais abrangente dá abertura para que os sujeitos possam organizar suas lembranças trajetórias e memórias, incluindo ali componentes de ordem pessoal e subjetivos, carregados de emoção.

Durante a entrevista-diálogo Maria Helena pode elencar as principais conquistas, mas também as dificuldades encontradas como treinadora. Cabe aqui ressaltar a atenção dada ao rigor metodológico. Apesar do conhecimento sobre a experiência de outras treinadoras e do contato com artigos e textos acadêmicos produzidos sobre o tema, no momento do diálogo tivemos uma postura de valorizar a fala. Deixar com que a entrevistada conduzisse o diálogo, detalhando sua história de vida e fazendo os apontamentos que julgava como aqueles mais relevantes. As intervenções dos entrevistadores não buscavam a confirmação de teorias ou o direcionamento da fala, mas sim a construção de um diálogo. Ao comentar a importância da escuta para a construção da ciência, Leão (2016) destaca que no fluxo da narrativa deve-se evitar uma postura inquisitiva. A autora prossegue:

Pensando em sentido ampliado, o momento das conversas com o Outro pode e deve ser entendido como um momento de descoberta, de abertura ao inesperado, tanto para o pesquisador quanto para o entrevistado. Em outras palavras, o momento é um espaço para o diálogo. (p. 32)

Ao desenvolver a escuta atenta, pudemos absorver a versão da história construída pela treinadora, que nos abriu novos horizontes, revelando em cada palavra seu empenho pela profissão e a dedicação com o qual tratou não apenas a equipe olímpica que comandou, mas também todas as equipes de base das quais lapidou talentos e alçou aos times adultos.

\section{Resultados e discussão: Nascida para o basquete}

Filha de um ex-jogador de futebol, Maria Helena Cardoso teve nove irmãs e um irmão. O basquete sempre fez parte da família e ela se lembra de ir, ainda criança, acompanhar as irmãs nos treinos, na pequena cidade de Descalvado, a aproximadamente 250 quilômetros de São Paulo (de acordo com dados, em 2016 o município tinha 30 mil habitantes). A relação com o esporte fez com que ela deixasse a casa dos pais precocemente: aos dezesseis anos de idade mudou-se para o município de Piracicaba (que em 2016 tinha 297 mil habitantes), a $150 \mathrm{~km}$ da família, todavia mais perto do sonho e da seleção brasileira. Rubio (2017) e Amato (2018) apontam que a migração causada pelo esporte é comum, e que o processo de mudança de cidade tem uma série de consequências para os 
esportistas, dentre elas a necessidade da construção de uma rede de apoio pessoal e o amadurecimento profissional.

Durante os primeiros anos, conciliou o basquete com o trabalho de professora em uma escola infantil, conforme relata Guedes (2016). Como atleta, foram 156 jogos com a camisa da seleção brasileira, com quatro participaçóes em mundiais. O mais especial deles disputado em 1971, na cidade de São Paulo, quando o Brasil ficou na terceira colocação - a conquista desta medalha fez Maria Helena repensar os rumos da carreira. Continuou em Piracicaba, mas como estudante de Educação Física e começou o trabalho nas equipes de base. Cinco anos depois de conquistar a medalha do mundial dentro de quadra, Maria Helena viu de longe a modalidade feminina ser incluída nos Jogos Olímpicos. Nascia ali o desejo de realizar mais um sonho.

Assumir a equipe adulta de Piracicaba foi uma grande barreira vencida por Maria Helena. Romariz, Votre e Mourão (2012) apontam que na cultura organizacional do esporte brasileiro as mulheres são relegadas ao trabalho com a base, enquanto as equipes de alto rendimento ficam sob comando dos homens. Maria Helena subverteu tal lógica e tirou ainda proveito dela. Quando passou a comandar o time principal, a técnica sempre teve a preocupação de mesclar jogadoras adultas com as mais jovens, adotando para isso um sistema de jogo unificado entre todas as equipes de base e adulta, moldando assim uma forma particular de trabalho. Em um ano e meio, conquistou uma Taça Brasil e dois campeonatos paulistas, o torneio regional mais importante do país. Era o passaporte necessário para assumir o comando da seleção brasileira, que passava por uma crise, conforme narrado na edição da revista Placar de 7 de abril de 1986. A seleção acabara de ser eliminada de um torneio internacional em Taiwan e as principais jogadoras, Paula e Hortência, haviam pedido dispensa do grupo por não concordar com os métodos do técnico anterior.

Os problemas no comando da seleção e os pedidos por Maria Helena coincidem com um momento onde internacionalmente as mulheres começavam a brigar por mais espaços em cargos administrativos e de comando, conforme aponta Amato (2018):

Durante a década de 1980, as mulheres começaram a se infiltrar nos altos níveis de gestão das organizações internacionais do esporte, entretanto estas eram exceções e tiveram pouca influência sobre o comando e poder masculino. Entre 1894 e 1981 não havia mulheres membros do COI, e a única forma de uma mulher ser nomeada seria se um homem sugerisse ou fizesse campanha em seu nome. (p. 91)

Além disso, o pedido de dispensa de várias atletas e o momento conturbado fora das quadras exigia que a escolhida para o cargo de técnica tivesse experiência anterior dentro de quadra. Lima (2017) aponta que, em eventos de crise, é fundamental que o técnico-mestre use suas experiências anteriores, como atleta, para tranquilizar e orientar os seus discípulos.

A primeira missão era conseguir uma vaga para os Jogos Olímpicos de Seul, dois anos depois. Mas o Brasil não conseguiu. Para Maria Helena, a falta de informações foi o principal obstáculo. “A gente não tinha nenhum 
conhecimento de nenhuma equipe. Foi a primeira vez que o Brasil saiu assim numa competição, pra tentar ir numa Olimpíada. E eu também, como técnica, era verde ainda. Estava há dois anos apenas na seleção, e as meninas eram novas, não tinham gabarito internacional. A gente chegou lá assim, cegas. Não tinha internet, não tinha intercâmbio, não tinha nada dos adversários. Então realmente a gente não conseguiu a classificação." (Maria Helena, comunicação pessoal, 20 de maio de 2018)

A saída, porém, foi por um curto período de tempo - apenas seis meses. Segundo Maria Helena, as questões políticas pesaram mais que as técnicas na decisão da Confederação de trocar o comando da equipe. Mesmo sem a vaga com a seleção brasileira a técnica esteve em Seul, 1988. Como expectadora, acompanhou das arquibancadas as partidas do basquete feminino. Com a ajuda do locutor esportivo Luciano do Valle, jornalista conhecido no Brasil por ter colaborado com o fomento dos esportes olímpicos, conseguiu uma credencial de imprensa para assistir alguns treinos.

Com três anos e meio de trabalho pela frente, Maria Helena teve em mãos uma das gerações mais talentosas do basquete brasileiro, com jogadoras reconhecidas internacionalmente como Paula e Hortência atuando juntas. Além das questões técnicas, ela também precisou saber lidar com a rivalidade fomentada entre as atletas, que atuavam nas duas principais equipes do Brasil e levavam um pouco dessa rivalidade para a equipe nacional.

No meio da trajetória olímpica, porém, havia a disputa dos Jogos PanAmericanos de Havana, em 1991. O Brasil chegou à decisão contra Cuba e os momentos que antecederam a decisão ainda estão vivos na memória de Maria Helena, que mostrou não se intimidar com nenhum tipo de pressão. Antes da partida decisiva, o ditador cubano Fidel Castro queria falar com algumas jogadoras brasileiras. A ordem, porém, foi vetada pela treinadora, que blindou as atletas. $\mathrm{O}$ encontro entre o dirigente cubano e as jogadoras ocorreu depois do jogo, no pódio, no momento em que ele colocou as medalhas douradas no pescoço das brasileiras. A campanha perfeita em Havana teve seis vitórias em seis jogos, como podemos ver na Tabela 1 abaixo:

Tabela 1

Jogos Pan-americanos - Havana/1991

Fase Preliminar

Brasil 87 - 84 Estados Unidos

Brasil 74-66 Canadá

Brasil $90-87$ Cuba

Brasil $83-56$ Argentina

Semifinal

Brasil 87-78 Canadá

Final

Brasil 97-76 Cuba 
Naquela edição dos Jogos Pan-Americanos o Brasil as seguintes jogadoras foram convocadas: Adriana Aparecida Santos, Ana Lúcia Mota, Hortência Marcari, Janeth Arcain, Joycenara Baptista, Maria Paula Gonçalves da Silva, Marta Sobral, Nádia Bento, Roseli do Carmo, Ruth de Souza, Simone Pontello e Vânia Hernandez de Souza. Vencer o torneio continental, todavia, era apenas uma parte do trabalho que tinha como meta a realização de um sonho. A classificação para os Jogos Olímpicos de Barcelona ocorreu durante um pré-olímpico disputado na cidade de Vigo, na Espanha (Tabela 2). Após duas derrotas nas primeiras partidas, a seleção brasileira ficou em situação delicada. Mas as vitórias sobre Zaire, Hungria e Austrália colocaram o Brasil nos Jogos Olímpicos.

Tabela 2

Pré-Olímpico de Vigo

\begin{tabular}{|c|}
\hline Pré-Olímpico de Vigo \\
\hline Brasil 77 x 89 China \\
Brasil $89 \times 91$ Tchecoslováquia \\
Brasil $99 \times 97$ Austrália \\
Brasil $102 \times 80$ Hungria \\
Brasil 105 x 65 Polônia \\
Brasil 90 x 60 Zaire \\
\hline Brasil $111 \times 57$ Rep. Dominicana \\
\hline
\end{tabular}

Fonte: CBB, 2019

A equipe base do Pan foi mantida no pré-olímpico, com pequenas alterações. Apenas Roseli do Carmo e Ana Lúcia foram substituídas por Hellen Luz e Maria Bertolotti. A realização do sonho de disputar uma edição olímpica veio com a esperança de chegar ao pódio olímpico. Mas o Brasil acabou sendo eliminado ainda na primeira fase, com uma derrota justamente diante da seleção cubana (Tabela 3), que um ano antes havia sido batida pelo Brasil em Havana.

Tabela 3

Jogos Olímpicos de Barcelona - 1992

\begin{tabular}{|l|c|}
\hline \multicolumn{2}{|c|}{ Preliminares } \\
\hline $30 / 07 / 1992$ & Brasil $85 \times 70$ Itália \\
\hline $01 / 08 / 1992$ & Brasil $88 \times 95$ Cuba \\
\hline $03 / 08 / 1992$ & Brasil $64 \times 76$ CEI \\
\hline \multicolumn{2}{|c|}{ Segunda fase } \\
\hline $05 / 08 / 1992$ & Brasil $62 \times 74$ Tchecoslováquia \\
\hline \multicolumn{2}{|c|}{ Decisão do $7^{\circ}$ lugar } \\
\hline $07 / 08 / 1992$ & Brasil $86 \times 83$ Itália \\
\hline
\end{tabular}


Para Maria Helena, tecnicamente o time estava preparado para conquistar uma medalha, mas a pressão da estreia e o encantamento com os Jogos Olímpicos acabaram atrapalhando o desempenho da equipe dentro de quadra. "Infelizmente eu acho que a equipe se deslumbrou, ao chegar na Vila, uma Vila são 10 mil atletas, com toda a diversão possível, e a equipe se deslumbrou, nunca tinha visto um negócio daquele e as meninas começaram sair do foco, então saiu realmente do foco. Mesmo assim, a gente teve a oportunidade naquela época, eu tinha certeza de ganhar uma medalha lá. Eu tinha certeza num jogo contra Cuba, que a gente perdeu na segunda prorrogação, que era o jogo daquelas oitavas fatídicas que se você perde não vai pra disputar medalha. E a gente perdeu na segunda prorrogação." (Maria Helena, comunicação pessoal, 20 de maio de 2018)

Encerrados os Jogos Olímpicos, era o momento de fechar o ciclo. $O$ pedido de demissão que chegou a ser ensaiado antes dos jogos foi formalizado, com uma carta diferente da inicialmente prevista, mais brando nas críticas ao comando do basquete nacional. Questionada sobre o motivo de ser a única mulher que comandou uma seleção nacional em Jogos Olímpicos, ela aponta uma série de renúncias que teve de fazer em virtude do trabalho. "Eu esqueci de mim, de casar, de filhos, de família. A minha família, meus filhos, eram os jogadores de basquete. A minha vida era o basquete. E normalmente a mulher, ela começa a trabalhar de técnica, aí ela é professora, o marido já não quer, não deixa. Então existe um machismo cultural no Brasil. A mulher, primeiro, não tem tempo, porque daí vem filho, não dá pra tocar, então você se dedica realmente ou você não consegue. Esse é um lado da coisa que eu acho que é o lado natural. Eu realmente sou apaixonada pelo basquete de uma forma assim, que pode ter alguém igual, mas eu duvido. Porque eu realmente vivia disso. Me realizei nisso, não me arrependo de nada que eu fiz, faria de novo, então esse lado, pra mim não fez falta." (Maria Helena, comunicação pessoal, 20 de maio de 2018)

Ao apontar que foi a única pessoa a "viver" para o esporte, Maria Helena toca em um ponto abordado por Kilty (2006). No entendimento da autora, é possível dividir os entraves para as carreiras de mulheres na função de técnicas esportivas em duas categorias: internas e externas.

As barreiras externas identificadas para a concessão de oportunidades profissionais
para treinadoras mulheres podem ser divididas em quatro subcategorias: (a)
avaliação desigual de competências, (b) contratação de diretores por similaridade,
(c) homofobia e (d) falta de mentoras mulheres. (...) As barreiras internas
identificadas pelos participantes como afetando as oportunidades profissionais
podem ser divididas em quatro subcategorias: (a) perfeccionismo, (b) falta de
assertividade, (c) inibição na promoção de realizaçóes e (d) alto estresse no
equilíbrio entre trabalho e vida. (p. 224-226, tradução dos autores)

Na mesma linha, mas partindo para uma divisão mais detalhada, LaVoi e Dutove (2012) consideram que é possível elencar em quatro diferentes níveis as barreiras enfrentadas pelas mulheres treinadoras

O primeiro nível mais proximal, o nível individual / intrapessoal, inclui fatores pessoais, biológicos e psicológicos, como cognição, emoções, crenças, valores, conhecimentos e personalidade do indivíduo [...] O próximo nível menos 
proximal, o nível interpessoal, é composto por influências sócio-relacionais, como colegas, um parceiro importante, amigos e pais. As configurações imediatas para o indivíduo, incluindo casa, escola ou local de trabalho, também estão incluídas neste nível. [...] O terceiro nível, o nível organizacional / estrutural, é definido por políticas organizacionais, descrições de cargos, práticas profissionais, uso do espaço e oportunidades (ou falta dele). [...] O quarto nível, e o mais distal, é o nível sociocultural, que abrange normas e sistemas culturais que afetam indiretamente as treinadoras. (p. 20, tradução dos autores)

Tanto as situações indicadas por Kilty quanto as elencadas por LaVoi e Dutove são absolutamente consistentes com os exemplos apontados por Maria Helena durante sua trajetória como técnica, não apenas na seleção brasileira, mas também diante de clubes. É importante ainda ressaltar que o trabalho da treinadora não foi extinto exatamente no momento de sua saída do comando da equipe nacional, deixando um legado que rendeu frutos em pouco tempo. Dois anos após Maria Helena deixar o comando da seleção, o Brasil foi campeão mundial de basquete feminino, na Austrália, sob o comando do técnico Miguel Ângelo da Luz. A base, porém, era a mesma que havia participado dos Jogos de Barcelona, com a repetição de sete atletas (Tabela 4).

Tabela 4

Atletas da seleção convocadas entre 1992 e 1994

\begin{tabular}{|c|c|}
\hline Barcelona -1992 & Austrália -1994 \\
\hline Adriana & Adriana \\
\hline Helen & Helen \\
\hline Hortência & Hortência \\
\hline Janeth & Janeth \\
\hline Paula & Paula \\
\hline Pontello & Pontello \\
\hline Ruth & Ruth \\
\hline Joyce & Alessandra \\
\hline Zezé & Cintia \\
\hline Marta Sobral & Dalila \\
\hline Nádia & Leila \\
\hline Vânia Hernandes & Roseli \\
\hline
\end{tabular}

Fonte: Fiba, 2019

Embalado pelo título mundial, o Brasil seguiria como uma potência no basquete feminino por alguns anos. Nos Jogos Olímpicos de Atlanta, em 1996, ainda sob comando do técnico Miguel Ângelo da Luz, a seleção brasileira conquistou a medalha de prata. Quatro anos depois, em Sydney-2000, Antônio Carlos Barbosa foi o técnico da equipe que conquistou a medalha de bronze.

Deixar a seleção brasileira, porém, não representou o fim a trajetória de Maria Helena na modalidade. Ela seguiu como treinadora de equipes nacionais. À frente da Ponte Preta, montou um esquadrão que conquistou do bicampeonato mundial nas temporadas de 1993 e 1994 . O maior orgulho, todavia, foi ver a equipe da Ponte Preta ganhar todos os torneios 
de base do estado de São Paulo no mesmo ano e promover um festival no qual as equipes eram formadas por jogadoras de diferentes idades, que conseguiam atuar juntas, já que o sistema de jogo era o mesmo desde as equipes infantis até o adulto.

Mesmo tendo a responsabilidade por comandar o time adulto, Maria Helena demonstra um sentimento de responsabilidade com a base, dando um suporte essencial a jovens atletas. Ao analisar o papel social do treinador, Lima (2017) aponta que:

No esporte, percebemos que, com frequência, jovens são lançados sem estarem ainda preparados para a tarefa. Ainda imaturos e, principalmente, despreparados em sua condição emocional, são colocados em tarefas em que o corpo pode até responder, porém, a mente não. Quando isso acontece, o resultado acaba sendo o fracasso. A reversão desse processo é difícil, lenta e, muitas vezes, impossível, se o mesmo não estiver preparado para arcar com o ônus da própria hybris. Daí a necessidade do preparar-se adequadamente para a "batalha". Estar preparado para cumprir a tarefa faz parte do período de instrução do herói e, como estamos propondo, do atleta também. Estar preparado não significa, necessariamente, alcançar a vitória, mas sim, estar apto para suportar a derrota, caso ela aconteça. $\mathrm{E}$ mais do que isso, aprender com ela, aproveitando seus ensinamentos. (p. 117)

Essa preparação dos jovens era uma obsessão para Maria Helena, que levou a mescla de trabalhos entre times de base e profissional para os outros clubes em que atuou: BCN Osasco, Vasco da Gama. No início dos anos 2000 teve uma experiência internacional, pela equipe do Mendibil. Após retornar ao Brasil, decidiu aposentar-se.

Em todos os trabalhos, Maria Helena sempre fez questão de repetir parte da comissão técnica. Para ela, o sucesso do trabalho do treinador está diretamente ligado ao entrosamento com os demais membros da comissão. Ela vê ainda como uma necessidade a mescla de profissionais de ambos os sexos nestes cargos. "Sempre vão achar que a mulher não é competente. $\mathrm{E}$ eu vou achar que uma equipe de trabalho não pode ser montada só de mulheres. Mas também não pode ser formada só de homens. Não só de basquete. Não só em todas as modalidades. Por quê? Porque o homem tem algumas qualidades que a mulher não tem. Mas a mulher tem outras, que o homem não tem. Então a junção dos dois, numa equipe de trabalho, é que dá o resultado. Então eu sentava com o Paulinho, que era o técnico da base, com a esposa dele que era técnica também da base, com a Heleninha que era a assistente e com o Hermes que era o preparador físico. Toda semana a gente se reunia. A ideia de quatro pessoas, de cinco, sendo dois homens e três mulheres, é que fazia o trabalho. Montava o trabalho. Desde a categoria de base até o olímpico. Nós estávamos a par do quê acontecia em tudo, os cinco. E é isso que dá o resultado. Então eu acredito que alguém há de perceber isso. Que numa equipe de trabalho da seleção feminina, tem que ter uma mulher. Tem que ter uma mulher. Porque a mulher tem a percepção. A mulher conhece a outra mulher. A mulher entra no vestiário. E ela consegue detectar os problemas de grupo antes dos homens. Os homens demoram um pouco mais. Ao contrário, o homem é mais prático, a mulher é mais ciumenta. Tem coisas que o homem é melhor e tem coisas que a mulher 
é melhor. Talvez um dia os dirigentes descubram isso e a gente melhore nesse aspecto." (Maria Helena, comunicação pessoal, 20 de maio de 2018)

$\mathrm{O}$ desejo de Maria Helena em ver dirigentes mais atentos às qualidades de homens e mulheres vai ao encontro da percepção de Souza de Oliveira (2002), que detecta nas mulheres que assumiram cargos de liderança uma mudança de postura, para poderem "provar" que tinham condiçóes de manterem o status alcançado. De acordo com a autora:

As técnicas, além de exercerem o lado técnico da profissão, exercitam o seu lado dito "masculino" e também o seu lado dito "feminino", como a flexibilidade, a docilidade, a capacidade de negociar, mediar e inovar, utilizando-se destes "atributos" quando lhes convém, ao comandarem suas equipes esportivas. (p. 22)

Única técnica olímpica do Brasil, Maria Helena acredita que deixou também um legado inspirador para as jogadoras que atuaram sob seu comando. Afastada das quadras, ela acompanha de longe o basquete nacional e, apesar de saber de todas as barreiras que são colocadas na trajetória de uma mulher para ser treinadora, espera um dia ver uma atleta que tenha comandado no cargo de técnica da seleção brasileira.

\section{Conclusões}

O exercício da escuta, permitindo que Maria Helena falasse sobre sua trajetória como técnica profissional e das barreiras enfrentadas para chegar ao comando de uma seleção nacional nos Jogos Olímpicos serviu não apenas como ilustração, mas demonstrou com clareza as dificuldades encontradas por aquelas que ousam ocupar um espaço tipicamente masculino. Os relatos da treinadora e sua vivência dentro de quadra estão em sinergia com os desafios encontrados por outros profissionais e descritos em outras pesquisas. É válido ainda destacar a naturalidade com a qual temas espinhosos, como a discriminação de gênero e a pressão realizada por pessoas que deveriam dar suporte ao trabalho realizado dentro de quadra surgem na fala da treinadora de maneira natural, não sendo necessária uma postura inquisitória, ou que cause o direcionamento de fala. A literatura sobre a presença de mulheres em funções de comando é variada, mas apresenta alguns pontos em comum. O objetivo do encontro com Maria Helena não foi levar à treinadora as barreiras apontadas por especialistas e pedir para que ela desse exemplos de quais foram os problemas encontrados por ela na carreira, classificando os problemas encontrados, mas sim ouvi-la atentamente e, a partir de então, buscar a teorização de que aquele não se tratava de um fenômeno isolado.

Finalizando, é preciso retomar o número marcante. Em trinta equipes olímpicas, apenas uma comandada por uma mulher. Há quase três décadas, o comando das modalidades femininas no Brasil em Jogos Olímpicos segue exclusivamente nas mãos de homens. Não por acaso, até hoje, quando anda pelas ruas, Maria Helena ainda é reconhecida como a técnica de uma equipe que comandou há quase três décadas. 


\section{Referências}

Acosta, R. V., \& Carpenter, L. J. (2017). Women in intercollegiate sport: A longitudinal, national study, thirty-seven-year. Recuperada de http:///ww w.acostacarpenter.org.

Adelman, M. (2004). A mulher como instrumento de poder no esporte de rendimento. III Fórum de debates sobre mulher \& esporte: mitos e verdades. São Paulo, SP.

Amato, J. F. (2018). Kairós: O momento da partida na história de vida de mulheres olimpicas brasileiras (Dissertação de mestrado). Escola de Educação Física e Esporte, Universidade de São Paulo, São Paulo. Recuperada de https://www.teses.usp.br/teses/disponiveis/39/39136/td e-09052018-131326/pt-br.php

Balbino, H. F. (2005). Pedagogia do treinamento: método, procedimentos pedagógicos e as múltiplas competências do técnico nos jogos desportivos coletivos (Tese de doutorado). Faculdade de Educação Física, Universidade Estadual de Campinas, Campinas-SP.

CBB. (2019). Confederação Brasileira de Basquete. Recuperada de https://ww w.cbb.com.br/

Fasting, K., \& Pfister, G. (2000). Female and male coaches in the eyes of female elite soccer players. European Physical Education Review, 6(1), 91-110.

Ferreira, H. J. (2012). O percurso de mulheres como técnicas esportivas no brasil (Dissertação de mestrado). Universidade Federal de Viçosa, Viçosa-MG

Fetter, J. C. S. S., \& Silva, E. M. (2011). A atleta, o técnico. O atleta, a técnica. In K. Rubio (Ed.), As mulheres e os esporte olimpico brasileiro (p.183-200). São Paulo, SP: Casa do Psicólogo.

FIBA. (2019). Federação Internacional de Basquete. Recuperada de http://ww w.fiba.basketball/

Goellner, S. (2006). Mulher e esporte no brasil: entre incentivos e interdições elas fazem história. Pensar a prática, 8(1), 85-100.

Guedes, C. (2016). Mulheres à cesta, basquete feminino no brasil. São Paulo, SP: Miss Lily.

Kilty, K. (2006). Women in coaching. The Sport Psychologist, 20(2), 222-234.

LaVoi, N. M., \& Dutove, J. K. (2012). Barriers and supports for female coaches: an ecological model. Sports Coaching Review, 1(1), 17-37.

Leão, L.I.C. (2018). Narratives and life stories in academic research: Reflections on the metod. In: K. Rubio. (Ed.). Biographical narratives: from the search for to the construction of a method (p.21-38). São Paulo, SP: Laços.

Lima, D.A.S (2017). A relação técnico atleta e o mito de quíron. In K. Rubio (Ed.), Esporte e mito (p.101-120). São Paulo, SP: Laços.

Reade, I., Rodgers, W., \& Norman, 1. (2009). The under-representation of women in coaching: a comparison of male and female canadian coaches at low and high levels of coaching. International Journal of Sports Science \& coaching, 4(4), 505-520.

Romariz, S., Votre, S., \& Mourão, 1. (2012). Representações de gênero no voleibol brasileiro: A imagem do teto de vidro. Movimento, 18(4), 219-237. 
Rubio, K. (2014) Memórias e narrativas biográficas de atletas olímpicos brasileiros. in: Autor (Ed.), Preservação da memória: A responsabilidade social dos jogos olímpicos. São Paulo, SP: Képos.

Rubio, K. (2017) Processos migratórios e deslocamentos: caminhos que levaram atletas de modalidades coletivas aos jogos olímpicos de Barcelona em 1992. Olimpianos - Journal of Olympic Studies, 1(1), 53-67.

Shaw, S., \& Hoeber, I. (2003). "A strong man is direct, and a direct woman is a bitch": Gendered discourses and their influence on employment roles in sport organizations. Journal of Sport Management, 17(4), 347-375.

Souza de Oliveira, G. A. (2002). Representações sociais de mulheres técnicas sobre o comando de equipes esportivas de alto nível. Rio de Janeiro, RJ: UGF.

Theberge, N. (1993). The construction of gender in sport: women, coaching, and the naturalization of difference. Social Problems, 40(3), 301-313. 